\title{
An Integrated Approach for Logistic Partner Selection in a Logistics Alliance
}

\author{
PANG Chunchao ${ }^{1}$, LIU LiShuai ${ }^{2 *}$ \\ (1 Financial Affairs Office of the Guangxi Zhuang Autonomous Region, Nanning 530022; \\ 2 Guilin University of Electronic Technology, Guilin 541004) \\ *1169917431@qq.com
}

\begin{abstract}
This study looks at selecting the partner in a logistics alliance as well as the intricate relationships between various factors. We use three research models herein. First, Interpretive Structural Modeling (ISM) establishes the criteria for the interrelationship structure, categorized according to their driving power and dependence. Second, because ISM does not provide any weighting associated with the criteria, we employ the Analytic Network Process (ANP) approach to calculate the weighted importance of the key factors and to identify those factors impacting the partner selection. Finally, TOPSIS method is used to obtain final ranking. To illustrate how the approach is used for the partner selection problem, an application of a real case in a company is conducted. The application has demonstrated the effectiveness and feasibility of the proposed model.
\end{abstract}

Key words: ISM, ANP, TOPSIS, Partner Selection, Logistics Alliance

\section{Introduction}

Partner is a key factor influence the performance of the logistic alliance. Partner selection is one of the most important processes of alliance management in logistic systems. It plays a decisive role in alliance management in which it will determine the input quality of partner. According to the strategic of enterprise, logistic alliance formed by appropriate partner should achieve the following objectives: (i) sharing investments and risks; (ii) accelerating project developments, and (iii) accessing resources and competences not available internally. The strategic alliances started its rapid growth as one strategic alternative since the 1990's, Although the existence of rich literature generated after the intensive growth of alliances as one important strategic option since the two last decades, the study mainly focus on two sides, namely the factors influencing partner selection and the model for partner selection.

Jagdev et al. [1] review high quality products are necessary precondition for entry into the market and for many manufacturers high quality is no longer the basis of competitive advantage, so cost and time to market are the basis of competitive advantage. Camarinha-Matos et al. [2] present a framework for partner selection and describe the functionalities in detail, but no techniques to make the trade off based on the cost and time are proposed. In Wang et al.'s [3] study, the costs and completion time of the subprojects bidden by the candidates are taken into consideration. Based on a comprehensive review of partner evaluation methods, Sarkis et al. [4] concluded that performance was the highest ranked factor, followed by delivery time and cost. According to the literature review, we are finding that partner selection decisions must not be exclusively based on cost, delivery time, risk criteria and that also a critical factor, such as partner compatibility need to be incorporated into the selection process. 
Many research studies have recently developed models to select appropriate partner. Chia Nan Wang et al. [5] proposed a model for partner selecting, the methodologies are constructed by the concepts of Data Envelopment Analysis (DEA) and grey model (GM). Burak Erkayman et al. [6] proposed a fuzzy multi-criteria decision making (MCDM) approach to effectively select the most appropriate provider. Zhongliang Yue et al. [7] introduce an approach to partner selection with linguistic values and intuitionistic fuzzy information under a group decision-making environment. Chong $\mathrm{Wu}$ [8] proposes a new fuzzy intelligent approach for partner selection in agile supply chains by using fuzzy set theory in combination with radial basis function artificial neural network. Chandra Prakash et al. [9] discuss an integrated model based on fuzzy analytic hierarchy process for evaluation and prioritization of selection criteria and fuzzy technique for order performance by similarity to ideal solution for the selection and development of reverse logistics partner. Peyman Akhavan et al. [10] proposed FQSPM-SWOT model for partner selection. Criteria of partners' evaluation are attained on the basis of combining strengths, weaknesses, opportunities and threats. Due to uncertainty of criteria, they are weighted using fuzzy quantitative strategic planning matrix. It can be concluded from these studies that the relationship between factors included in the partner selection model being neglected. Any factor in the model could be related to, or dependent on another. Weights of the factors alone in the partner selection model are important; besides, weights that are to be determined as a result of reciprocal interactions of the factors are also substantial. Evaluating the interdependence between factors should contribute to the objectivity of decisions.

In this study, a hybrid model was proposed for the partner selection process. Both ISM and TOPSIS- ANP methods were applied within the framework of the proposed model. The use of these three models as a hybrid for partner selection problems enabled selection of the most appropriate partner by taking into consideration the dependence among factors, which distinguishes this study from others in the literature. The ISM method is used to systematically explore the causal relationships among various factors. The ANP method is used to determine the relative weight of interdependence criteria; the TOPSIS method is used to rank the candidates in terms of overall performance with respect to multiple interdependence criteria. ISM is a multicriteria decision-making methodology and an interactive learning process whereby a set of dissimilar directly and indirectly related elements are structured into a completed systemic model [11]. This technique transforms unclear and poorly articulated system models into visible and well-defined models. Taking into account the interdependence of criteria used in the decision-making process. The ANP method produces a more accurate weighting of selection criteria, since it enables consideration of the dependence among factors in decision-making problems. Although the proposed model was applied to the partner selection process of a specific company, it can be adapted to other personnel selection scenarios with slight modifications.

This paper is organized as follows. Section 2 present criteria for partner selection. Section 3 introduces the proposed methodology in detail and summarizes the calculation steps, including ISM, ANP and TOPSIS. Section 4 presents an application of the proposed model. The final Section 5 gives the conclusions.

\section{Criteria for partner selection}

Whether an enterprise can become partner, mainly consider the famous 3C principle, namely compatibility, capability and commitment. compatibility is mainly manifested in the enterprise strategic planning and operations, capacity matching mainly embodied in complementary resources, commitment is embodied in the will of the cooperation invested time, energy and resources. In views of the above criteria and the evaluation index system principle, the index system in 
influencing partner selection was given, as shown in Fig. 1.

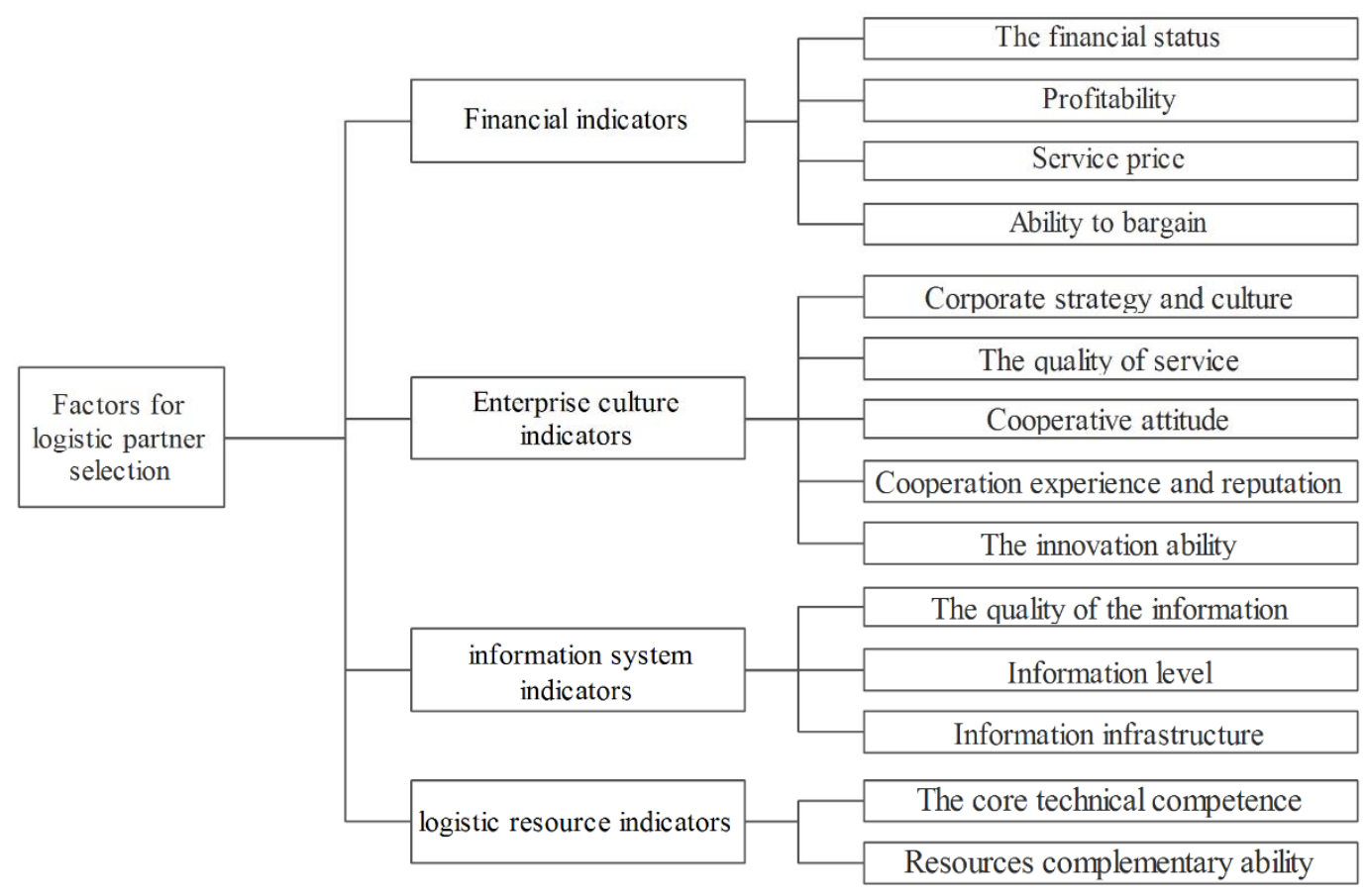

Figure 1.Criteria carcass of partner selection

\section{Method}

\subsection{Interpretive Structural Modeling}

Interpretive structural modeling (ISM) is such a methodology. It can be used for identifying and summarizing relationships among specific variables, which define a problem or an issue. It provides us a mean by which order can be imposed among various elements of a system [12]. Which variables are driving other relationships is reflected in the result. With this technique, the overall structure is portrayed in the form of a directed graph or digraph [13]. The advantages of ISM are that it is a structural representation of the original problem situation and hence can be communicated easily and effectively to others [14]. This process is computer aided and systematic and considers every possible pairs of variables involved. The pairs include links directly from the participants' responses or through transitive inference. The various steps in this technique are as follows:

Step 1: Different enablers of variables related to the issue are identified and constitute element set $S=\left(S_{1}, S_{2}, \cdots S_{n}\right)$.

Step 2: A structural self-interaction matrix (SSIM) is developed for these variables. SSIM indicates pair-wise relationship among these variables. The relationship is given as:

$$
S_{i} R S_{j}=\left\{\begin{array}{l}
1 \quad \text { there is a direct binary relationship beteween } S_{i} \text { and } S_{j} \\
0 \text { there is not a direct binary relationship beteween } S_{i} \text { and } S_{j}
\end{array} \quad(i, j=1,2, \cdots n) .\right.
$$

Step 3: A reachability matrix $(\mathrm{RM})$ is then developed from this SSIM.

Step 4: Based on all of the above, a directed graph (digraph) is constructed and only those transitive links (indirect links) are retained whose interpretation is crucial).

Step 5: The nodes of the elements are then replaced with statements to form the ISM model 
from this digraph.

\subsection{Analytic Network Process}

ANP is the general form of the analytic hierarchy process. It is used in multiple criteria decision making to release the restriction of a hierarchical structure that integrates linkages and feedback into the decision system in order to evaluate the overall cumulative importance of all indicators within an evaluation model. ANP is able to include interdependent relationships among its elements by capturing the composite weights through the development of a super matrix. Generally, ANP is the method used for solving unstructured and semi-structured decision problems in a social economic system. The ANP method consists of the following steps:

Step1: According to the index system influence partner selection and the relationship between indicators, which are obtained by ISM structure model, ANP model was constructed.

Step2: Build the comparison matrix between index set and sub-index .Conducting pairwise comparisons on the elements. Placing the eigenvectors in pairwise comparison matrices within the unweighted supermatrix $W$.

Step3: Weighting the blocks of the unweighted supermatrix, by the corresponding priorities of the clusters, so that it can be column stochastic and get weighted supermatrix $\bar{W}$. This condition is needed to derive meaningful limiting priorities.

Step4: Raising the weighted super matrix $\bar{W}$ to limiting powers until the weights converge and remain stable, can get limit supermatrix $W^{\infty}$. It given as:

$$
W^{\infty}=\lim _{i \rightarrow \infty} \frac{1}{m} \sum_{i=1}^{m} \overline{W^{i}} .
$$

\subsection{TOPSIS}

The TOPSIS was first developed by Hwang and Yoon [15]. According to this technique, the best alternative would be the one that is nearest to the positive ideal solution and farthest from the negative ideal solution [16]. The TOPSIS method consists of the following steps:

Step 1: Establish a decision matrix for the ranking. where ${ }^{Q_{i}}$ denotes the alternatives ${ }^{i}$, $i=1,2, \cdots N ; \quad I_{j}$ represents $j$ th attribute or criterion, $j=1,2 \cdots M$, related to ${ }^{i \text { th }}$ alternative; and $x_{i j}$ is a crisp value indicating the performance rating of each alternative $Q_{i}$ with respect to each criterion $I_{j}$.so $N \times M_{\text {values forms matrix }} X=\left\lfloor X_{i j}\right\rfloor_{N \times M}$.

Step 2: Calculate the normalized decision matrix $R=\left\lfloor r_{i j}\right\rfloor_{N \times M}$.

Step 3: Calculate the weighted normalized decision matrix by multiplying the normalized decision matrix $R=\left\lfloor r_{i j}\right\rfloor_{N \times M}$ by its associated weight vector $R=\left(w, w, \cdots, w_{M}\right)^{T}$. The weighted normalized value ${ }^{u_{i j}}$ calculated as ${ }^{u_{i j}}=w_{j} r_{i j}$.

Step 4: Determine the positive-ideal ${ }^{+}$and negative-ideal ${ }^{U_{j}^{-}}$solutions. 


$$
U_{j}^{+}=\max \left(U_{i j} \mid i=1,2, \cdots N\right) . \quad U_{j}^{-}=\min \left(U_{i j} \mid i=1,2, \cdots N\right) .
$$

Step 5: Calculate the separation measures, using the m-dimensional Euclidean distance. The separation of each alternative from the positive-ideal solution ${ }_{i}^{+}$is given as:

$$
S_{i}^{+}=\sqrt{\sum_{j=1}^{M}\left(U_{i j}-U_{j}^{+}\right)^{2}}, i=1,2, \cdots N
$$

Similarly, the separation of each alternative from the negative-ideal solution $S_{i}^{-}$is as follows:

$$
S_{i}^{-}=\sqrt{\sum_{j=1}^{M}\left(U_{i j}-U_{j}^{-}\right)^{2}}, i=1,2, \cdots N .
$$

Step 6: Calculate the relative closeness to the idea solution and rank the performance order. The relative closeness of the alternative ${ }^{Q_{i}}$ with respect to ${ }^{U_{j}^{+}}$can be expressed as:

$$
d_{i}^{*}=\frac{S_{i}^{-}}{S_{i}^{+}+S_{i}^{-}}, i=1,2, \cdots N
$$

Where the $d_{i}^{*}$ index value lies between 0 and 1.The larger the index value means the better the performance of the alternatives.

\section{Case Study}

We present a case study conducted in Hebei province of chain to demonstrate the practicality of the proposed approaches. Logistics enterprise A mainly engaged in third-party transportation and warehousing business, the original business scope mainly for north China and east China region. With the enlargement of the business and competition, it starts offer transportation services in 20 cities, such as Shenzhen, Fuzhou, Xiamen, however, the existing logistics resources cannot meet the needs of the development of enterprises. Therefore, the enterprise must find partners and run as a cooperative in order to response to customer demand rapidly. After collecting a large number of relevant data, it determines six dimensions $Q_{i}(i=1,2 \cdots, 6)$.

\subsection{Analyzing the relationship between factors by ISM}

Now, for analyzing the influence of these variables in influencing partner selection, a contextual relationship is established through expert panel opinion and discussion sessions held with them. The relationship between any two variables is considered and the initial reachability matrix $A$ is depicted as shown. 


$$
A=\left[\begin{array}{ccccccccccccccc}
i / j & s_{1} & s_{2} & s_{3} & s_{4} & s_{5} & s_{6} & s_{7} & s_{8} & s_{9} & s_{10} & s_{11} & s_{12} & s_{13} & s_{14} \\
s_{1} & 0 & 0 & 0 & 0 & 0 & 0 & 0 & 0 & 0 & 0 & 0 & 0 & 0 & 0 \\
s_{2} & 1 & 0 & 0 & 0 & 0 & 0 & 0 & 0 & 0 & 0 & 0 & 0 & 0 & 0 \\
s_{3} & 0 & 1 & 0 & 0 & 0 & 0 & 0 & 0 & 0 & 0 & 0 & 0 & 0 & 0 \\
s_{4} & 0 & 0 & 1 & 0 & 0 & 0 & 0 & 0 & 0 & 0 & 0 & 0 & 0 & 0 \\
s_{5} & 0 & 0 & 0 & 0 & 0 & 0 & 0 & 0 & 1 & 0 & 0 & 1 & 1 & 0 \\
s_{6} & 0 & 1 & 0 & 0 & 0 & 0 & 0 & 0 & 0 & 0 & 0 & 0 & 0 & 0 \\
s_{7} & 0 & 0 & 0 & 0 & 0 & 1 & 0 & 0 & 0 & 0 & 0 & 0 & 0 & 0 \\
s_{8} & 0 & 0 & 0 & 1 & 0 & 0 & 0 & 0 & 0 & 0 & 0 & 0 & 0 & 0 \\
s_{9} & 0 & 1 & 0 & 0 & 0 & 1 & 0 & 0 & 0 & 0 & 0 & 0 & 1 & 0 \\
s_{10} & 0 & 0 & 0 & 0 & 0 & 1 & 0 & 0 & 0 & 0 & 0 & 0 & 0 & 0 \\
s_{11} & 0 & 0 & 0 & 0 & 0 & 1 & 0 & 0 & 0 & 1 & 0 & 0 & 0 & 0 \\
s_{12} & 0 & 0 & 0 & 0 & 0 & 0 & 0 & 0 & 0 & 0 & 1 & 0 & 0 & 0 \\
s_{13} & 0 & 0 & 0 & 0 & 0 & 1 & 0 & 0 & 0 & 0 & 0 & 1 & 0 & 1 \\
s_{14} & 0 & 0 & 0 & 0 & 0 & 0 & 1 & 0 & 0 & 0 & 0 & 0 & 0 & 0
\end{array}\right]
$$

After incorporating the transitivity, the final reachability matrix $R$ is obtained as present.

$$
R=\left[\begin{array}{ccccccccccccccc}
i / j & s_{1} & s_{2} & s_{3} & s_{4} & s_{5} & s_{6} & s_{7} & s_{8} & s_{9} & s_{10} & s_{11} & s_{12} & s_{13} & s_{14} \\
s_{1} & 1 & 0 & 0 & 0 & 0 & 0 & 0 & 0 & 0 & 0 & 0 & 0 & 0 & 0 \\
s_{2} & 1 & 1 & 0 & 0 & 0 & 0 & 0 & 0 & 0 & 0 & 0 & 0 & 0 & 0 \\
s_{3} & 1 & 1 & 1 & 0 & 0 & 0 & 0 & 0 & 0 & 0 & 0 & 0 & 0 & 0 \\
s_{4} & 1 & 1 & 1 & 1 & 0 & 0 & 0 & 0 & 0 & 0 & 0 & 0 & 0 & 0 \\
s_{5} & 1 & 1 & 0 & 0 & 1 & 1 & 1 & 0 & 1 & 1 & 1 & 1 & 1 & 1 \\
s_{6} & 1 & 1 & 0 & 0 & 0 & 1 & 0 & 0 & 0 & 0 & 0 & 0 & 0 & 0 \\
s_{7} & 1 & 1 & 0 & 0 & 0 & 1 & 1 & 0 & 0 & 0 & 0 & 0 & 0 & 0 \\
s_{8} & 1 & 1 & 1 & 1 & 0 & 0 & 0 & 1 & 0 & 0 & 0 & 0 & 0 & 0 \\
s_{9} & 1 & 1 & 0 & 0 & 0 & 1 & 1 & 0 & 1 & 1 & 1 & 1 & 1 & 1 \\
s_{10} & 1 & 1 & 0 & 0 & 0 & 1 & 0 & 0 & 0 & 1 & 0 & 0 & 0 & 0 \\
s_{11} & 1 & 1 & 0 & 0 & 0 & 1 & 0 & 0 & 0 & 1 & 1 & 0 & 0 & 0 \\
s_{12} & 1 & 1 & 0 & 0 & 0 & 1 & 0 & 0 & 0 & 1 & 1 & 1 & 0 & 0 \\
s_{13} & 1 & 1 & 0 & 0 & 0 & 1 & 1 & 0 & 0 & 1 & 1 & 1 & 1 & 1 \\
s_{14} & 1 & 1 & 0 & 0 & 0 & 1 & 1 & 0 & 0 & 0 & 0 & 0 & 0 & 1
\end{array}\right]
$$

From the final reachability matrix, for each factor, reachability set and antecedent sets are derived. The reachability set represents the factor itself and the other factor that it may impact, whereas the antecedent set consists of the factor itself and the other factor that may impact it. The intersection of these sets is then derived. The top level in the ISM hierarchy is occupied by the factors for which the reach ability and the intersection sets are the same. These factors will not lead the other factors above their own level and once identified, they are removed from consideration. Then, the same process is repeated to find out the factors in the next level. This process is continued until the level of each factor is found. These levels help in building the digraph and the ISM model. In this way, the entire process is completed in nine iterations and nine levels have been identified as Fig. 2.

\section{1 calculate the weights by ANP Method}

Even though the interrelationship of all factors can be classified using the ISM method, the importance of the factors is difficult to be presented by using the same approach. Therefore, we implement the ANP method to rank the importance of all factors in this section. The ANP model showed in Fig. 3. 


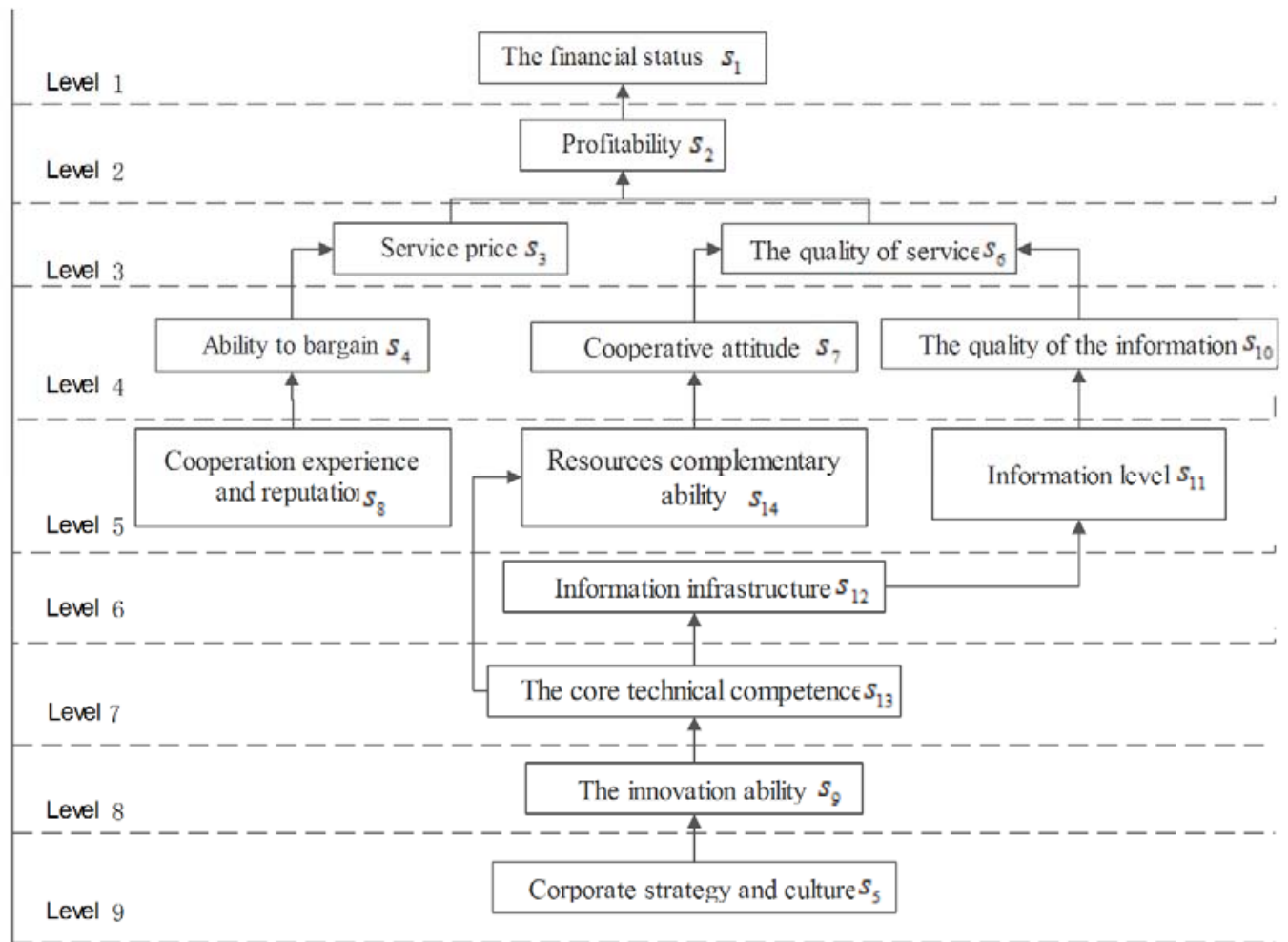

Figure 2.ISM-based Model for Partner Selection

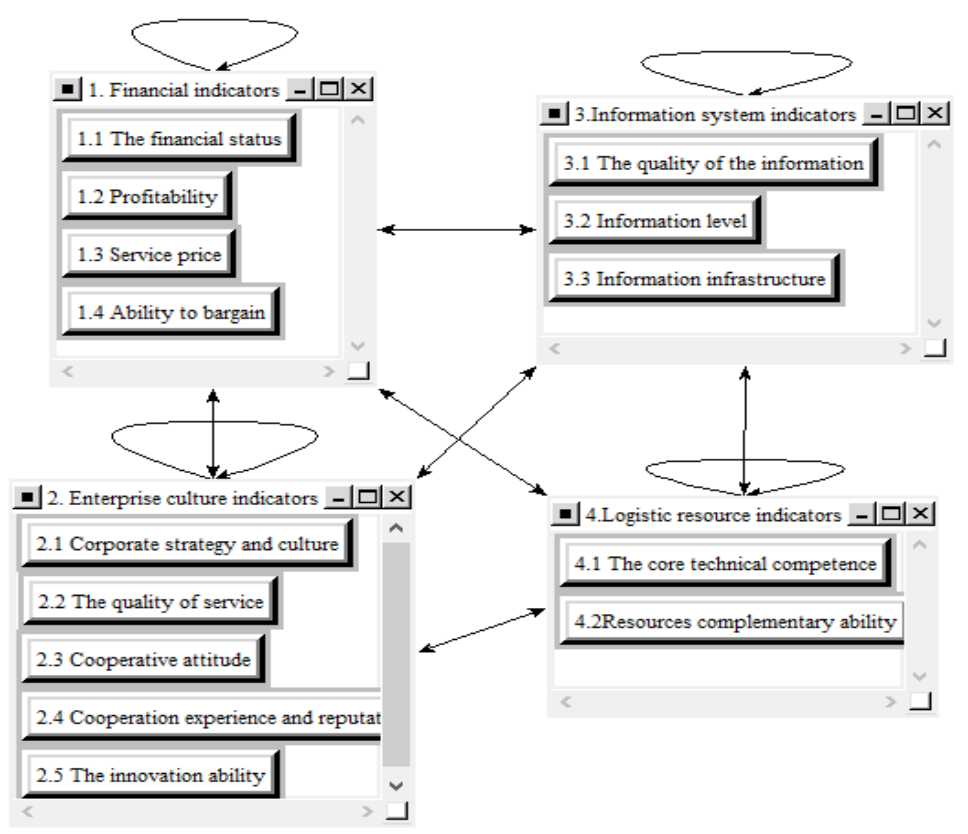

Figure 3.ANP-based Model of Indexes Influencing Partner Selection 


$W^{\infty}=\left[\begin{array}{llllllllllllll}0.0566 & 0.0566 & 0.0566 & 0.0566 & 0.0566 & 0.0566 & 0.0566 & 0.0566 & 0.0566 & 0.0566 & 0.0566 & 0.0566 & 0.0566 & 0.0566 \\ 0.0963 & 0.0963 & 0.0963 & 0.0963 & 0.0963 & 0.0963 & 0.0963 & 0.0963 & 0.0963 & 0.0963 & 0.0963 & 0.0963 & 0.0963 & 0.0963 \\ 0.0442 & 0.0442 & 0.0442 & 0.0442 & 0.0442 & 0.0442 & 0.0442 & 0.0442 & 0.0442 & 0.0442 & 0.0442 & 0.0442 & 0.0442 & 0.0442 \\ 0.0467 & 0.0467 & 0.0467 & 0.0467 & 0.0467 & 0.0467 & 0.0467 & 0.0467 & 0.0467 & 0.0467 & 0.0467 & 0.0467 & 0.0467 & 0.0467 \\ 0.1267 & 0.1267 & 0.1267 & 0.1267 & 0.1267 & 0.1267 & 0.1267 & 0.1267 & 0.1267 & 0.1267 & 0.1267 & 0.1267 & 0.1267 & 0.1267 \\ 0.0624 & 0.0624 & 0.0624 & 0.0624 & 0.0624 & 0.0624 & 0.0624 & 0.0624 & 0.0624 & 0.0624 & 0.0624 & 0.0624 & 0.0624 & 0.0624 \\ 0.0367 & 0.0367 & 0.0367 & 0.0367 & 0.0367 & 0.0367 & 0.0367 & 0.0367 & 0.0367 & 0.0367 & 0.0367 & 0.0367 & 0.0367 & 0.0367 \\ 0.0964 & 0.0964 & 0.0964 & 0.0964 & 0.0964 & 0.0964 & 0.0964 & 0.0964 & 0.0964 & 0.0964 & 0.0964 & 0.0964 & 0.0964 & 0.0964 \\ 0.1130 & 0.1130 & 0.1130 & 0.1130 & 0.1130 & 0.1130 & 0.1130 & 0.1130 & 0.1130 & 0.1130 & 0.1130 & 0.1130 & 0.1130 & 0.1130 \\ 0.0605 & 0.0605 & 0.0605 & 0.0605 & 0.0605 & 0.0605 & 0.0605 & 0.0605 & 0.0605 & 0.0605 & 0.0605 & 0.0605 & 0.0605 & 0.0605 \\ 0.0523 & 0.0523 & 0.0523 & 0.0523 & 0.0523 & 0.0523 & 0.0523 & 0.0523 & 0.0523 & 0.0523 & 0.0523 & 0.0523 & 0.0523 & 0.0523 \\ 0.0368 & 0.0368 & 0.0368 & 0.0368 & 0.0368 & 0.0368 & 0.0368 & 0.0368 & 0.0368 & 0.0368 & 0.0368 & 0.0368 & 0.0368 & 0.0368 \\ 0.1005 & 0.1005 & 0.1005 & 0.1005 & 0.1005 & 0.1005 & 0.1005 & 0.1005 & 0.1005 & 0.1005 & 0.1005 & 0.1005 & 0.1005 & 0.1005 \\ 0.0710 & 0.0710 & 0.0710 & 0.0710 & 0.0710 & 0.0710 & 0.0710 & 0.0710 & 0.0710 & 0.0710 & 0.0710 & 0.0710 & 0.0710 & 0.0710\end{array}\right]$

We weight the unweighted supermatrix first. We then raise the weighted supermatrix to limiting powers in order to capture all the interactions and to obtain a convergence outcome. After get the weighted supermatrix $W^{\infty}$, we present the priorities in Table 1.

Table 1.The Weights of Indexes Influencing Partner Selection

\begin{tabular}{|c|c|c|c|c|}
\hline Dimensions & Weight & Factors & Weight & Priorities \\
\hline \multirow{4}{*}{ Financial $p_{1}$} & \multirow{4}{*}{0.2439} & The financial status $p_{11}$ & 0.0566 & 9 \\
\hline & & Profitability $p_{12}$ & 0.0963 & 5 \\
\hline & & Service price $p_{13}$ & 0.0442 & 12 \\
\hline & & Ability to bargain $p_{14}$ & 0.0467 & 11 \\
\hline \multirow{5}{*}{$\begin{array}{l}\text { Enterprise } \\
\text { culture } p_{2}\end{array}$} & \multirow{5}{*}{0.4351} & Corporate strategy and culture $p_{21}$ & 0.1267 & 1 \\
\hline & & The quality of service $\quad p_{22}$ & 0.0624 & 7 \\
\hline & & Cooperative attitude $p_{23}$ & 0.0367 & 14 \\
\hline & & Cooperation experience and reputation $p_{24}$ & 0.0964 & 4 \\
\hline & & The innovation ability $p_{25}$ & 0.1130 & 2 \\
\hline \multirow{3}{*}{$\begin{array}{l}\text { Information } \\
\text { system } p_{3}\end{array}$} & \multirow{3}{*}{0.1495} & The quality of the information $p_{31}$ & 0.0605 & 8 \\
\hline & & Information level $p_{32}$ & 0.0523 & 10 \\
\hline & & Information infrastructure $p_{33}$ & 0.0368 & 13 \\
\hline \multirow{2}{*}{$\begin{array}{c}\text { Logistic } \\
\text { resource } p_{4}\end{array}$} & \multirow{2}{*}{0.1715} & The core technical competence $p_{41}$ & 0.1005 & 3 \\
\hline & & Resources complementary ability $p_{42}$ & 0.0710 & 6 \\
\hline
\end{tabular}

\subsection{Determine Final Rank by TOPSIS Method}

At this stage of the application, expert team members evaluated each candidate according to each criterion and developed a decision matrix. Evaluation showed that all the criteria are "benefit criteria". Expert team members used crisp numbers from 1 to 10 so as to evaluate the candidates on the basis of these criteria. After the decision matrix was developed, this matrix was normalized, in this calculation, criteria weights obtained by using ANP were used. Decision matrix is presented in Table 2. Normalized decision matrix is presented as matrix $U$. 
Table 2.Assessment Matrix of Six Companies

\begin{tabular}{|c|c|c|c|c|c|c|}
\hline & $Q_{1}$ & $Q_{2}$ & $Q_{3}$ & $Q_{4}$ & $Q_{5}$ & $Q_{6}$ \\
\hline$p_{11}$ & 4 & 5 & 5 & 6 & 3 & 4 \\
\hline$p_{12}$ & 5 & 6 & 6 & 7 & 4 & 6 \\
\hline$p_{13}$ & 8 & 6 & 8 & 4 & 5 & 5 \\
\hline$p_{14}$ & 6 & 5 & 6 & 4 & 5 & 5 \\
\hline$p_{21}$ & 6 & 5 & 6 & 6 & 8 & 7 \\
\hline$p_{22}$ & 6 & 4 & 4 & 8 & 6 & 7 \\
\hline$p_{23}$ & 4 & 4 & 4 & 4 & 6 & 7 \\
\hline$p_{24}$ & 4 & 6 & 4 & 4 & 6 & 5 \\
\hline$p_{25}$ & 6 & 6 & 8 & 6 & 6 & 4 \\
\hline$p_{31}$ & 4 & 7 & 6 & 5 & 6 & 4 \\
\hline$p_{32}$ & 8 & 8 & 6 & 4 & 8 & 5 \\
\hline$p_{33}$ & 8 & 6 & 6 & 6 & 8 & 5 \\
\hline$p_{41}$ & 6 & 7 & 5 & 6 & 7 & 4 \\
\hline$p_{42}$ & 8 & 6 & 6 & 4 & 5 & 5 \\
\hline
\end{tabular}

\begin{tabular}{|c|c|c|c|c|c|c|c|c|c|c|c|c|c|c|}
\hline \multirow{6}{*}{$U=$} & [0.0201 & 0.0342 & 0.0233 & 0.0219 & 0.0485 & 0.0254 & 0.0120 & 0.0320 & 0.0453 & 0.0181 & 0.0255 & 0.0182 & 0.0415 & 0.0400 \\
\hline & 0.0251 & 0.0411 & 0.0175 & 0.0183 & 0.0404 & 0.0169 & 0.0120 & 0.0480 & 0.0453 & 0.0317 & 0.0255 & 0.0137 & 0.0484 & 0.0300 \\
\hline & 0.0251 & 0.0411 & 0.0233 & 0.0219 & 0.0485 & 0.0169 & 0.0120 & 0.0320 & 0.0604 & 0.0272 & 0.0191 & 0.0137 & 0.0346 & 0.0300 \\
\hline & 0.0301 & 0.0479 & 0.0117 & 0.0146 & 0.0485 & 0.0339 & 0.0120 & 0.0320 & 0.0453 & 0.0227 & 0.0128 & 0.0137 & 0.0415 & 0.0200 \\
\hline & 0.0151 & 0.0274 & 0.0146 & 0.0183 & 0.0646 & 0.0254 & 0.0180 & 0.0480 & 0.0453 & 0.0272 & 0.0255 & 0.0182 & 0.0484 & 0.0250 \\
\hline & 0.0201 & 0.0411 & 0.0146 & 0.0183 & 0.0565 & 0.0297 & 0.0210 & 0.0400 & 0.0302 & 0.0181 & 0.0159 & 0.0114 & 0.0277 & 0.0250 \\
\hline
\end{tabular}

Positive and negative ideal solutions were calculated by using the data in U. Positive ideal and negative ideal solutions were calculated as follows:

$U^{+}=(0.0301,0.0479,0.0233,0.0219,0.0646,0.0339,0.0210,0.0480,0.0604,0.0317,0.0255,0.0182,0.0484,0.0400)$

$U^{-}=(0.0151,0.0274,0.0117,0.0146,0.0404,0.0169,0.0120,0.0320,0.0302,0.0181,0.0128,0.0114,0.0277,0.0200)$

Using equation the relative closeness to the idea solution of each candidate is then calculated. Calculated values are ordered and listed in Table 3. According to the closeness coefficient, the ranking order of the five personnel is $Q_{5}>Q_{3}>Q_{2}>Q_{1}>Q_{4}>Q_{6}$. The results indicate that $Q_{5}$ is the best candidate with closeness coefficient value of 0.55117 .

Table 3.The Ranking Order and Assessment Result for Partner Selection

\begin{tabular}{|c|c|c|c|c|}
\hline & $s_{i}^{+}$ & $s_{i}^{-}$ & $d^{*}$ & Rank \\
\hline$Q_{1}$ & 0.03768 & 0.03777 & 0.50061 & 4 \\
\hline$Q_{2}$ & 0.03773 & 0.04127 & 0.52241 & 3 \\
\hline$Q_{3}$ & 0.03649 & 0.04160 & 0.53277 & 2 \\
\hline$Q_{4}$ & 0.04158 & 0.03803 & 0.47768 & 5 \\
\hline$Q_{5}$ & 0.03595 & 0.04415 & 0.55117 & 1 \\
\hline$Q_{6}$ & 0.04770 & 0.02894 & 0.37759 & 6 \\
\hline
\end{tabular}




\section{Conclusions}

The issue of partner selection is central to a company' $\mathrm{s}$ aim of achieving the benefits. Inappropriate decisions in this area may also impact other functions of management. Therefore, the partner selection problem should be solved scientifically. In this study, we establish the influence factor system and proposed an effective model for the partner selection problem using ISM, ANP and TOPSIS methods. First, we use ISM to systematically explore the causal relationships among various factors. Second, we implement ANP and TOPSIS methods to select the partner in a logistic alliance on the basis of ISM. The ANP method was used to identify the importance weights of the factors in the selection process and the TOPSIS method was adopted in ranking of the candidates. Finally, the proposed model was applied within a case, as observed from the case study, the model can be efficiently used in partner selection and provides support for further research on multiple-criteria optimization decision.

\section{References}

[1] Jagdev HS, Browne J. The extended enterprise - a context for manufacturing. Prod Plan Control 9(3):216-245(1998).

[2] Camarinha-Matos LM, Cardoso T.Selection of partners for a virtual enterprise. In: Camarinha-Matos LM, Afsarmanesh H (eds) Pro-VE'99 book, infrastructure for virtual enterprises: networking industrial enterprise s. Kluwer Academic Publishers, Boston Dordrecht London, pp. 259-278(1999).

[3] Wang D, Yung KL, Ip WH. A heuristic genetic algorithm for subcontractor selection in a global manufacturing environment. IEEE Trans Syst Man Cybern C 31(2):189-198(2001).

[4] Sarkis J, Talluri S. model for strategic supplier selection. Trans Eng Manage 38(1):18-28

[5] ChiaNanWang,NhuTyNguyen,ThanhTuyenTran,BuiBichHuong,Jung-FaTsai.A Study of the Strategic Alliance for EMS Industry: The Application of a Hybrid DEA and $\operatorname{GM}(1,1)$ Approach[J].The Scientific World Journal(2015).

[6] BurakErkayman, EminGundogar, AysegulYılmaz, G.Bordogna,P.Melin. An Integrated Fuzzy Approach for Strategic Alliance Partner Selection in Third-Party Logistics [J]. The Scientific World Journal(2012).

[7] ChandraPrakash,M.K.Barua. An analysis of integrated robust hybrid model for third-party reverse logistics partner selection under fuzzy environment[J]. Resources, Conservation\&Recycling, (2016)

[8] ZhongliangYue. An intuitionistic fuzzy projection -based approach for partner selection[J]. Applied Mathematical Modelling (2013).

[9] ChongWu,David Barnes. Partner selection in agile supply chains: a fuzzy intelligent approach[J]. Production Planning \& Control(2014).

[10] PeymanAkhavan,SasanBarak,HamidrezaMaghsoudlou,JurgitaAntuchevičienè.FQSPM-SWOT for strategic alliance planning and partner selection; case study in a holding car manufacturer company[J].Technological and Economic Development of Economy(2015).

[11] E. Fontela, “The future societal bill: methodological alternatives,” Futures, vol. 35, no. 1, pp. $25-36,(2003)$. 
[12] Singh, M.D., Shankar R., Narain R., \& Agarwal A.An interpretive structural modeling of knowledge management in engineering industries. Journal of Advances in Management Research,1(1), 28-40, (2003).

[13] Sharma, B.P., Singh, M.D., \& Kumar, A. Knowledge sharing barriers: An integrated approach of ISM. Singapore: AHP (2012).

[14] Attri, R., Dev, N., \& Sharma, V. Interpretive structural modeling (ISM) approach: An overview. Research Journal of Management Sciences, 2(2), 3-8 (2012)..

[15] Hwang, C.L., \& Yoon, K.. Multiple attribute decision making: Methods and applications, a state of the art survey. New York: Springer-Verlag (1981).

[16] Ertugrul, I.,\&Karakasoglu, N. Performance evaluation of Turkish cement firms with fuzzy analytic hierarchy process and TOPSIS methods. Expert Systems with Applications, (2007), in press. 